\title{
Examining Self-Efficacy and Self-Esteem in Healthcare Students Participating in an Interprofessional Critical Care Simulation
}

\author{
Michelle L Allen ${ }^{1}$, Maureen Emlund ${ }^{1}$, Michal Kozdronkiewicz ${ }^{1}$, Kristen Bayer ${ }^{1}$, Mary Groll2 ${ }^{2}$ Carrie Slezak ${ }^{3}$, \\ Tanya Wadhwa ${ }^{5}$, Brett Barich ${ }^{5}$, Alexander D. Pinc ${ }^{1}$, Kryzstof Gabarz', Elizabeth Heintz², Joshua Mueller ${ }^{2}$, \\ Rose Ann Mathai ${ }^{3} \&$ Julie Bach $^{4}$ \\ ${ }^{1}$ Department of Nursing, Dominican University, River Forest, IL, USA \\ ${ }^{2}$ Department of Physician Assistant Studies, Dominican University, River Forest, IL, USA \\ ${ }^{3}$ Department of Nutrition and Dietetics, Dominican University, River Forest, IL, USA \\ ${ }^{4}$ Department of Social Work, Dominican University, River Forest, IL, USA \\ ${ }^{5}$ Department of Post-Baccalaureate Studies, Dominican University, River Forest, IL, USA \\ Correspondence: Michelle L Allen, Department of Nursing, Dominican University, River Forest, IL, USA \\ Tel:1-708-524-6272. E-mail: mallen@dom.edu
}

Received: July 11, 2018 Accepted: August 6, 2018 Online Published: August 15, 2018

doi:10.5539/gjhs.v10n9p81 URL: https://doi.org/10.5539/gjhs.v10n9p81

\begin{abstract}
Background: Interprofessional education (IPE) is becoming increasingly encouraged in healthcare. However, a lack of consensus exists in how IPE should be provided. The research at hand examines changes in self-efficacy and self-esteem in 132 nursing, dietetic, physician assistant, and social work students when participating in a critical care simulation. The simulation focused on a septic patient requiring cardiopulmonary resuscitation.

Method: This quantitative, repeated measures and correlational study utilized the Generalized Self-Efficacy Scale and Rosenberg Self-Esteem Scale to examine a possible relationship between self-efficacy and self-esteem. In addition, exploration of changes in self-efficacy and self-esteem after participating in the cardiopulmonary simulation was conducted.

Results: There was a statistically significant medium, positive correlational relationship between self-efficacy and self-esteem in healthcare students participating in a cardiopulmonary resuscitation simulation $(\mathrm{p}<0.001)$. Healthcare students did not experience statistically significant gains in self-efficacy and self-esteem $(\mathrm{p}>0.05)$. During debriefing, students expressed experiencing role confusion when working with each other.
\end{abstract}

Conclusion: More IPE experiences, including in mock code simulations, is necessary to enhance communication, collaboration, and prevent role confusion.

\section{Highlights:}

- More interprofessional education is necessary to prevent role confusion

- Self-efficacy and self-esteem have a positive correlation in IPE critical care simulation

- Healthcare students did not have significant gains in self-efficacy and self-esteem

Keywords: interprofessional education, critical care, self-esteem, self-efficacy, health science education

\section{Introduction}

In 2010, the World Health Organization (WHO) encouraged interprofessional education (IPE) as a method for enhancing collaborative practice in healthcare (World Health Organization [WHO], 2010). Gilbert, Yan, and Hoffman (2010) defined IPE as education when at least two professions learn together about collaboration. Learning together can occur through the utilization of simulation.

Faculty at one university, across four departments, sought to understand pre-licensure healthcare students' self-efficacy and self-esteem when collaborating and learning together. The four departments included: nursing, nutrition and dietetics, physician assistant studies, and social work. More specifically, the purpose of this correlational study was to examine the relationship between healthcare students' self-efficacy and self-esteem 
before and after participating in care of a critically ill septic patient requiring cardiopulmonary resuscitation.

\section{Review of the Literature}

\subsection{Call for IPE}

Historically, many universities have focused on multiprofessional education (MPE) as opposed to IPE, which misses the mark on social identity, acceptance, and collaboration among healthcare students (Roodbol, 2010). MPE focuses on healthcare students learning core subjects together; however, it does not translate into the healthcare students' gains in communication and collaboration (Barr \& Coyle, 2013). MPE encourages students to learn next to one another without necessarily requiring interaction or discussion; whereas IPE requires students to interact while learning with each other (Keijsers, Dreher, Tanner, Forde-Johnston, \& Thompson, 2016; World Health Organization, 2010). As such, a call for IPE has been gaining momentum.

In addition to the appeal for IPE made by WHO (2010), other organizations have recommended incorporating IPE, rather than MPE, such as the Institute of Medicine and National League for Nursing (National League for Nursing $[N L N], 2015)$. Furthermore, many healthcare education accrediting bodies, such as the Commission on Collegiate Nursing Education (CCNE) encourage IPE (Zorek \& Raehl, 2012). Schmitt, Gilbert, Brandt, and Weinstein (2013) identified that IPE is necessary for healthcare students' preparation and is 'coming of age.'

\subsection{Research in IPE}

Lapkin, Jevett-Jones, and Gilligan (2013) conducted a systematic review on nine research studies and found that healthcare students' perceptions towards interprofessional collaboration can be enhanced when being educated together. Similarly, Darlow et al. (2014) found statistically significant gains in dietetic, medical, physiotherapy, and radiation therapy students' attitudes towards interprofessional collaboration, team skills, and readiness to collaboratively learn following participation in an eleven hour interprofessional education program $(p<0.01)$.

However, the literature lacks consensus on how interprofessional education should be delivered within the confines of a university, including use of simulation (Kusnoor \& Stelljes, 2016). Palaganas, Epps, and Raemer (2013) recommend simulation as a possible progressive method for IPE within healthcare curriculum. Simulation mimics a true-to-life setting, one in which safe learning can occur during the most stressful of patient situations. Specifically, simulation allows for physical and psychological safety; including the ability to learn from mistakes in an environment in which an unstable mock patient will not experience harm (Turner \& Harder, 2018).

A quasi-experimental study conducted by Alinier, Harwood, Harwood, Montague, Huish, Ruparelia, and Antuoermo (2014) involved 237 nursing, pharmacy, paramedic, radiography, and physiotherapy students. There were statistically significant increases in the students' confidence, knowledge of the other professions, and greater appreciation for IPE experiences when participating in a four hour simulation session $(\mathrm{p}<0.05)$. Simulation in a healthcare laboratory setting may be an ideal method for IPE as it allows for communication and collaboration practice, though the impact on healthcare students requires further investigation (Poore, Cullen, \& Schaar, 2014).

\subsection{Theoretical Framework}

The research was guided by the Interprofessional Education Collaborative (IPEC) Core Competencies: values and ethics, roles and responsibility, interprofessional communication, and teams and teamwork (Interprofessional Education Collaborative Expert Panel, 2011). The IPEC Core Competencies have been used in over 60 different professions to enhance patient safety and quality improvement outcomes (Interprofessional Education Collaborative, 2016). As such, the IPEC Core Competencies were agreed to be utilized during the first planning meeting involving faculty from all four of the different health professions. Throughout the planning process, faculty contributed to specific learner outcomes, including creating the script for the standardized patient and high-fidelity mannequin. On the four consecutive simulation days, faculty were required to be present and assist with answering students' questions and offering feedback to the participants during debriefing.

\subsection{Bandura's Theory of Self-Efficacy}

While the IPEC Core Competencies served as the agreed upon values, Bandura's Theory of Self-Efficacy contributed to the theoretical framework of the study. Self-efficacy is the notion that one has the ability to cope during a stressful encounter (Bandura, 1977). Working in healthcare, particularly in an emergency setting with critically ill patients is known to be stressful; this stress has negative implications on healthcare providers' health and wellness (Hunsaker, Chen, Maughan, \& Heaston, 2015; Koinis, Giannou, Drantaki, Angelaina, Stratou, \& Saridi, 2015). Being in a heightened state of stress can contribute to healthcare worker burnout in emergency and critical care settings (Moss, Good, Gozal, Kleinpell, \& Sessler, 2016; Schooley, Hikmet, Tarcan, \& Yorgancioglu, 2016). 
In healthcare education, simulation is a leaner-centered educational strategy that encourages students to develop their knowledge, skills, and attitudes about patient care (Cheng, Morse, Rudolph, Arab, Runnacles, \& Eppich, 2016). Simulation has the ability to recreate the stressful encounter and push healthcare students to practice advocating for critically ill patients through the use of varying fidelity mannequins and standardized patients (Arnold, Johnson, Tucker, Malec, Henrickson, \& Dunn, 2009; Meyer, Marzen-Groller, Myers, Busenhart, Wuagh, \& Stegenga, 2014; Shinnick \& Woo, 2017). However, it was unknown to the researchers how or if healthcare students' self-esteem was related to self-efficacy when placed in a simulated patient resuscitation event.

\subsection{Study Design}

This quantitative, repeated measures and correlational study was conducted in the spring term of the 2018 academic year. The study was approved by the Institutional Review Board prior to implementation. All four groups of healthcare students were provided and requested to watch the American Heart Association's 2015 training video of advanced cardiac life support. The nursing students were trained on how to work the defibrillator during their critical care didactic course.

Since simulation provides a realistic healthcare setting and hands-on learning, the research methodology incorporated the use of a high-fidelity mannequin and a standardized patient in a simulation laboratory. Prior to the start of the simulation, all participants were given a letter of introduction, letter of consent, and filled out surveys on self-efficacy and self-esteem. Participants were made aware that they were able to withdraw at any time and their grades would not be impacted. Participation in the research was not mandatory. After completing the pre-simulation surveys, all participants were given a standardized change-of-shift report on a septic pneumonia patient situated in an emergency room waiting for an in-patient bed assignment.

From there, the group of eight to ten healthcare students participated in the 30 minute simulation. Following the simulation, the post-surveys were completed and compensation (in the form of a candy bar of choice) was provided and debriefing occurred respectively. The 30 minute debriefing included standardized questions and a follow-up question and answer session with faculty from all four healthcare specialties. All-in-all, there were 16 groups of eight to ten healthcare students participating in each 30 minute simulation.

\subsection{Sample and Setting}

In one university in suburban Chicago, 144 healthcare students were invited to participate in research focusing on changes in self-efficacy and self-esteem when participating in an interprofessional, critical care simulation. The students were invited to sign up for 30 minute time slots based upon their individual availability; sixteen time slots over the course of four days were available for students to sign up. Each time slot consisted of eight to ten students: three to four nursing, one to two physician assistant, two to three nutrition, and two to three social work students.

Out of the 144, eight chose not to participate and five participants were removed due to incompletion of surveys. In total, 132 healthcare students served as research participants in the critical care interprofessional simulation. The participants consisted of undergraduate and graduate level students from nursing, physician assistant, nutrition and dietetics, and social work. However, if students opted not to participate in the research, they were still given the opportunity to participate in the simulation as it contributed to the students meeting their course and program outcomes.

Table 1. Participant Demographics

\begin{tabular}{lll}
\hline Student Type & Frequency & Percent \\
\hline Registered Nurse & 46 & 34.8 \\
Physician Assistant & 28 & 21.2 \\
Registered Dietitian & 36 & 27.3 \\
Social Work & 22 & 16.7 \\
Total & 132 & 100.0 \\
\hline
\end{tabular}




\subsection{Study Instruments}

\subsubsection{Generalized Self-Efficacy Scale}

In order to gauge self-efficacy, the ten-item, four-point Likert-scale, Generalized Self-Efficacy Scale was utilized. The scale was selected due to fitting Bandura's Theory of Self-Efficacy, along with demonstration of good reliability and validity. Across 23 nations, the reliability for the Generalized Self-Efficacy Scale had a Cronbach alpha's range of 0.76 to 0.90 (Schwarzer \& Jersualem, 1995). In addition, the Generalized Self-Efficacy Scale demonstrated criterion-related validity when examining positive emotions (Schwarzer \& Jersualem, 1995). The Generalized Self-Efficacy Scale has been used in various research studies focusing on self-efficacy of healthcare providers and pre-licensure nursing students (Duggleby, Cooper, \& Penz, 2009; George, Locasto, Pyo, \& Cline, 2017).

\subsubsection{Rosenberg Self-Esteem Scale}

The Rosenberg Self-Esteem Scale was used to measure the participants' self-esteem. The scale was chosen based upon the operational definition that self-esteem is the feeling of worth of one-self (Rosenberg, 1965). This ten question, four-point Likert-scale instrument was chosen due to demonstrating good test-retest reliability of 0.85 and internal consistency with an alpha of 0.88 (Fleming \& Courtney, 1980; Sibler \& Tippett, 1965). Furthermore, criterion-related validity was demonstrated between the Rosenberg Self-Esteem Scale and self-regard at 0.78 as measured by the Self-Rating Scale (Fleming \& Courtney, 1980). The Rosenberg Self-Esteem Scale has been used in various studies involving university students (Abouserie, 1994; Martin-Albo, Nuñez, Navarro, \& Grijalvo, 2007). As such, the Rosenberg Self-Esteem Scale was given before and after participating in the IPE simulation.

\subsubsection{Simulation Development and Implementation}

The scenario was developed as a result of collaborative efforts by nursing, nutrition, physician assistant, and social work faculty; the simulation took place in the confines of a safe laboratory setting in a College of Health Sciences. The unique learning needs, including learner and program outcomes for each group of students, was woven in the script. At the same time, the overarching learning outcome focused on interprofessional communication and collaboration. The script included a simulated patient and family member within an emergency room setting.

The scenario centered on a patient, simulated by a high-fidelity mannequin, experiencing sepsis related to a new diagnosis of pneumonia, poor nutrition, and ultimately requiring advanced cardiac life support resuscitation. At the nursing station, the students were given access to an electronic health record, a telephone, resuscitation code cart, defibrillator, an automated medication dispensing system, and drug books. The students were able to call lab, radiology, pharmacy, and an emergency room attending physician. Nursing and physician assistant students tended to the ailments of the patient, whereas the nutrition students tended to the nutrition needs of the patient. In order to obtain a nutrition assessment, the nutrition students had to communicate with the patient and the patient's son. The social work students tended to the son's psychosocial needs during resuscitation efforts, including addressing questions about advanced directives. Following the successful resuscitation of the patient, all learners participated in debriefing.

\subsubsection{Debriefing}

Following the simulation, participants shared their thoughts during debriefing, which included degriefing. The debriefing occurred over 30 minutes using standardized questions and was not part of the research as participants filled out the surveys immediately following the simulation and prior to the debriefing. The questions focused on: the participants' providing a summary of the scenario, what went well during the simulation, opportunities to enhance the team's collaboration, impact of collaborating with other healthcare team members on personal self-efficacy and self-esteem, and if the participants would recommend the simulation to other healthcare students. The degriefing allowed for the participants to express their fears, concerns, questions, anxiety, and other feelings about the simulation.

\section{Results}

After compiling the data, it was placed in SPSS for statistical analysis. Initially, testing was conducted for the entire healthcare student sample using a paired-samples t-test on percentage changes in self-efficacy and self-esteem. Analysis involved examining changes in scores for the Rosenberg Self-Esteem and Generalized Self-Efficacy Scales. For self-esteem, there was not a statistically increase in scores from pre-simulation $(M=31.61$, $S D=3.56)$ to post-simulation $(M=31.64, S D=4.21), t(131)=0.104, p=0.917$ (two-tailed). The mean increase was 0.03 with a $95 \%$ confidence interval ranging from -0.55 to 0.61 . For self-efficacy, there was not a statistically significant increase in in scores from pre-simulation $(M=23.15, S D=4.19)$ to post-simulation $(M=23.45, S D=4.45)$, 
$t(131)=1.337, p=0.183$ (two-tailed). The mean increase in self-efficacy scores was 0.30 with a $95 \%$ confidence interval ranging from -0.15 to 0.75 .

Prior to examining for a correlation, a scatterplot was used to assess for potential outliers. Normality, linearity, and homoscedasticity were not violated. Since no outliers were identified, the correlation was assessed. The relationship between the changes in self-efficacy and self-esteem when participating in an interprofessional critical care simulation was examined using a Pearson product-moment correlation coefficient. There was a medium, positive correlation between self-efficacy and self-esteem between the two variables, $r=0.46, n=132$, $\mathrm{p}<0.001$ with higher levels of changes in self-efficacy associated with changes in higher levels of self-esteem.

Further assessment examined if a relationship existed between both the changes in self-efficacy and self-esteem and student type. There was not a statistically significant correlation between changes in self-efficacy and the type of student when participating in the simulation, $r=0.08, n=132, p=0.36$. However, a statistically significant relationship between changes in self-esteem and student type was identified. There was a small, positive correlation between the two variables, $r=0.172, n=132, p=0.49$.

From there, partial correlation was used to explore the relationship between percentage change in self-efficacy and percentage change in self-esteem, while controlling for type of healthcare student. There was a moderate, positive, partial correlation between percentage change in self-efficacy and percentage change in self-esteem controlling for healthcare student type, $r=0.460, n=132, p<0.001$, with high levels of percentage change in self-efficacy being associated with high levels of percentage change in self-esteem. An inspection of the zero order correlation $(r=0.460)$ suggested that controlling for the healthcare student type had an effect on the strength of the relationship between these two variables.

Table 2. Changes from Time 1 to Time $2(n=132)$

\begin{tabular}{lllll}
\hline Concept & Time $1 \boldsymbol{M}(\boldsymbol{S D})$ & Time $2 \boldsymbol{M}(\boldsymbol{S D})$ & $\mathbf{9 5 \%}$ CI & p-value \\
\hline Self-Efficacy & $23.15(4.19)$ & $23.45(4.45)$ & -0.15 to 0.75 & 0.183 \\
Self-Esteem & $31.61(3.56)$ & $31.64(4.21)$ & -0.55 to 0.61 & 0.197 \\
\hline
\end{tabular}

Table 3. Correlation between Percentage Change Self-Efficacy and Self-Esteem Controlling for Healthcare Student Type $(n=132)$

\begin{tabular}{llll}
\hline & $\mathbf{1}$ & $\mathbf{2}$ & $\mathbf{3}$ \\
\hline 1. Student Type & - & 0.080 & $0.172^{*}$ \\
2. Percentage Change in Self-Efficacy & 0.080 & - & $0.460^{* *}$ \\
3. Percentage Change in Self-Esteem & $0.172^{*}$ & $0.460^{* *}$ & - \\
\hline
\end{tabular}

$* \mathrm{p}<0.05,{ }^{* *} \mathrm{p}<0.001$.

\section{Discussion}

When viewing the simulations live, the researchers found the students experiencing role confusion. Many of the healthcare students voiced their lack of knowledge about each other's scopes; this lack of knowledge likely contributed to the students question roles and responsibilities of the different disciplines, including self-identified role confusion. This role confusion may have contributed to the lack of statistically significant changes in self-efficacy and self-esteem. However, the statistically significant change in the pre-licensure social work students' self-efficacy and self-esteem may be related to all of the students being at the graduate level and older in age than the other groups of students.

Olenick, Allen, and Smego (2010) identified that the purpose of interprofessional education is to begin to dispel confusion about professional identities and thus needs to be practiced. As this was the first time that all of the students collaborated with each other, the findings demonstrate the need for further interprofessional education. Khalili, Orchard, Spence Laschinger, and Farah (2013) found that by solely focusing on educating healthcare students about their uniprofessional identities, confusion about interprofessional education and collaboration is perpetuated. However, Poore, Cullen, and Schaar (2014) have described using simulation in IPE as a possible method to dissolve the silos and promote greater understanding and collaboration. 
Furthermore, a lack of self-efficacy and self-esteem contributes to potential problems in the long-haul. Multiple studies have identified that a lack of self-efficacy and self-esteem in healthcare workers contributes to a weakening in moral resilience and less likely to speak up during patient care challenges (Roussin, Larraz, Jamieson \& Maestre, 2018; Rushton, 2016). As a result, healthcare workers experience burnout, compassion fatigue, and patients are placed at risk for poor outcomes (Dewa, Loong, Bonato, \& Trojanowski, 2017; Nowakowska, Rasińska, \& Głowacka, 2016). Faculty can help healthcare students become more comfortable collaborating during challenging patient encounters through the use of psychologically safe teaching strategies, such as IPE simulation, (Roussin et al., 2018).

\subsection{Limitations}

This research study was conducted at one university within metropolitan Chicago. A recommendation for follow-up research would to incorporate multiple sites. In addition, the methodology did not incorporate a fully-developed mixed method approach using focus groups or interviews. A recommendation for further research would be to incorporate focus groups as well as examining the impact of an interprofessional cardiopulmonary resuscitation simulation over time. Potential future research could include examining the impact of debriefing on the healthcare students' self-efficacy and self-esteem; a recommendation would be to provide the surveys following debriefing.

\section{Conclusion}

This research begins to offer a glimpse into the impact of incorporating interprofessional education on nursing, nutrition, physician assistant, and social work students' self-efficacy and self-esteem when participating in a high-fidelity resuscitation simulation. It became clear that more opportunities involving IPE are valuable as the teaching and learning in silos perpetuated role confusion in healthcare students when exposed to a single IPE experience. Further research involving IPE and simulation, particularly in an emergency resuscitation event, on students' self-efficacy and self-esteem is encouraged.

\section{Acknowledgements}

The researchers would like to thank President Donna Carroll and Dean Kavita Dhanwada for their support of simulation in healthcare education. This research did not receive any specific grant from funding agencies in the public, commercial, or not-for-profit sectors.

\section{Competing Interests Statement}

The authors declare that there are no competing or potential conflicts of interest.

\section{References}

Abouserie, R. (1994). Sources and levels of stress in relation to locus of control and self esteem in university students. Educational Psychology, 14(3), 323-330. https://doi.org/10.1080/0144341940140306

Alinier, G., Harwood, C., Harwood, P., Montague, S., Huish, E., Ruparelia, K., \& Antuofermo, M. (2014, April). Immersive clinical simulation in undergraduate health care interprofessional education: Knowledge and perceptions. Clinical Simulation in Nursing, 10(4), e205-e216. https://doi.org/10.1016/j.ecns.2013.12.006

Arnold, J. L., Johnson, L. M., Tucker, S., Malec, J. F., Henrickson, S. E., \& Dunn, W. F. (2009, January/February). Evaluation tools in simulation learning: Performance and self-efficacy in emergency response. Clinical Simulation in Nursing, 5(1), e35-e43. https://doi.org/10.1016/j.ecns.2008.10.003

Bandura, A. (1977). Self-efficacy: Towards a unifying theory of behavioral change. Psychological Review, 8(42), 191-215. https://doi.org/10.1037/0033-295X.84.2.191

Barr, H., \& Coyle, J. (2013). Introducing interprofessional education. In S. Loftus, T. Gerzina, J. Higgs, S. Smith, \& E. Duffy (Eds.), Educating health professionals (pp. 185-196). https://doi.org/10.1007/978-94-6209-353-9_16

Cheng, A., Morse, K. J., Rudolph, J., Arab, A. A., Runnacles, J., \& Eppich, W. (2016). Learner-Centered Debriefing for Health Care Simulation Education. Simulation in Healthcare: The Journal of the Society for Simulation in Healthcare, 11(1), 32-40. https://doi.org/10.1097/SIH.0000000000000136

Darlow, B., Coleman, K., McKinlay, E., Donovan, S., Beckingsale, L., Gray, B., ... Pullon, S. (2015, June 4). The positive impact of interprofessional education: A controlled trial to evaluate a programme for health professional students. BMC Medical Education, 15(98), 1-9. https://doi.org/10.1186/s12909-015-0385-3

Dewa, C. S., Loong, D., Bonato, S., \& Trojanowski, L. (2017). The relationship between physician burnout and 
quality of healthcare in terms of safety and acceptability: A systematic review. BMJ Open, 7(6). https://doi.org/10.1136/bmjopen-2016-015141

Duggleby, W., Cooper, D., \& Penz, K. (2009, November). Hope, self-efficacy, spiritual well-being, and job $\begin{array}{llll}\text { satisfaction. Journal of Advanced } & \text { Nursing, 65(11), 2376-2385. }\end{array}$ https://doi.org/10.1111/j.1365-2648.2009.05094.x

Fleming, J. S., \& Courtney, W. A. (1980). The dimensionality of self-esteem: Some results for a college sample. Journal of Personality and Social Psychology, 5(), 921-929. https://doi.org/10.1037/0022-3514.39.5.921

George, L., Locasto, L. W., Pyo, K. A., \& Cline, T. A. (2017, March). Effect of the dedicated education unit on nursing student self-efficacy: A quasi-experimental research study. Nurse Education in Practice, 23(), 48-53. https://doi.org/10.1016/j.nepr.2017.02.007

Gilbert, J. H., Yan, J., \& Hoffman, S. J. (2010, Fall). A WHO report: Framework for action on interprofessional education and collaborative practice. Journal of Allied Health, 39(3, Part 2), 196-197. Retrieved from https://pdfs.semanticscholar.org/91e8/44994b5846ca2a32accc73846087bed70eee.pdf

Hunsaker, S., Chen, H., Maughan, D., \& Heaston, S. (2015). Factors That Influence the Development of Compassion Fatigue, Burnout, and Compassion Satisfaction in Emergency Department Nurses. Journal of Nursing Scholarship, 47(2), 186-194. https://doi.org/10.1111/jnu.12122

Interprofessional Education Collaborative. (2016). Core competencies for interprofessional collaborative practice: 2016 update. Retrieved from https://www.ipecollaborative.org/resources.html

Interprofessional Education Collaborative Expert Panel. (2011). Core competencies for interprofessional collaborative practice: Report of an expert panel. Retrieved from Interprofessional Education Collaborative: https://www.aacom.org/docs/default-source/insideome/ccrpt05-10-11.pdf?sfvrsn=77937f97_2

Keijsers, C., Dreher, R., Tanner, S., Forde-Johnston, C., \& Thompson, S. (2016). Interprofessional education in $\begin{array}{lllll}\text { geriatric medicine. } & \text { European }\end{array}$ https://doi.org/10.1016/j.eurger.2016.01.011

Koinis, A., Giannou, V., Drantaki, V., Angelaina, S., Stratou, E., \& Saridi, M. (2015). The impact of healthcare workers job environment on their mental-emotional health. Coping strategies: The case of a local general hospital. Health Psychology Research, 3(1). https://doi.org/10.4081/hpr.2015.1984

Khalili, H., Orchard, C., Spence Laschinger, H. K., \& Farah, R. (2013, June 18). An interprofessional socialization framework for developing an interprofessional identity among health professions students. Journal of Interprofessional Care, 27(6), 448-453. https://doi.org/10.3109/13561820.2013.804042

Kusnoor, A. V., \& Stelljes, L. A. (2016, December). Interprofessional learning through shadowing: Insights and lessons learned. Medical Teacher, 38(12), 1278-1284. https://doi.org/10.1080/0142159X.2016.1230186

Lapkin, S., Levett-Jones, T., \& Gilligan, C. (2013, February). A systematic review of the effectiveness of interprofessional education in health professional programs. Nurse Education Today, 33(2), 90-102. https://doi.org/10.1016/j.nedt.2011.11.006

Martin-Albo, J., Nunez, J. L., Navarro, J. G., \& Grijalvo, F. (2007, November). The Rosenberg Self-Esteem Scale: Translation and validation in university students. The Spanish Journal of Psychology, 10(2), 458-467. https://doi.org/10.1017/S1138741600006727Pub

Meyer, M., Marzan-Groller, K., Myers, S., Busenhart, C., Waugh, S., \& Stegenga, K. (2014, August). Simulation as a learning experience: Perceptions of new RNs. Clinical Simulation in Nursing, 10(8), 384-394. https://doi.org/10.1016/j.ecns.2014.03.002

Moss, M., Good, V. S., Gozal, D., Kleinpell, R., \& Sessler, C. N. (2016). An Official Critical Care Societies Collaborative Statement: Burnout Syndrome in Critical Care Health Care Professionals: A Call for Action. American Journal of Critical Care, 25(4), 368-376. https://doi.org/10.4037/ajcc2016133

National League for Nursing. (2015). Interprofessional collaboration in education and practice: A living document from the National League for Nursing [Educational standards]. Retrieved from http://www.nln.org/docs/default-source/default-document-library/ipe-ipp-vision.pdf?sfvrsn=14

Nowakowska, I., Rasińska, R., \& Głowacka, M. D. (2016). The influence of factors of work environment and burnout syndrome on self-efficacy of medical staff. Annals of Agricultural and Environmental Medicine, 23(2), 304-309. https://doi.org/10.5604/12321966.1203895 
Olenick, M., Allen, L. R., \& Smego, R. A. (2010, November 25). Interprofessional education: A concept analysis. Advances in Medical Education and Practice, 1(), 75-84. https://doi.org/10.2147/AMEP.S13207

Palaganas, J. C., Epps, C., \& Raemer, D. B. (2013, December 30). A history of simulation-enhanced interprofessional education. Journal of Interprofessional Care, 28(2), 110-115. https://doi.org/10.3109/13561820.2013.869198

Poore, J. A., Cullen, D. L., \& Schaar, G. L. (2014, May). Simulation-based interprofessional education guided by Kolb's Experiential Learning Theory. Clinical Simulation in Nursing, 10(5), e241-e247. https://doi.org/10.1016/j.ecns.2014.01.004

Roodbol, P. F. (2010, April 22). Multiprofessional education to stimulate collaboration: A circular argument and its consequences. GMS Zeitschrift für Medizinische Ausbildung, 27(2), 1-4. https://doi.org/10.1007/s12507-010-0011-7

Roussin, C. J., Larraz, E., Jamieson, K., \& Maestre, J. M. (2018). Psychological Safety, Self-Efficacy, and Speaking Up in Interprofessional Health Care Simulation. Clinical Simulation in Nursing, 17, 38-46. https://doi.org/10.1016/j.ecns.2017.12.002

Rosenberg, M. (1965). Society and the adolescent self-image. Princeton, NJ: Princeton University Press. https://doi.org/10.1515/9781400876136

Rushton, C. H. (2016). Moral Resilience: A Capacity for Navigating Moral Distress in Critical Care. AACN Advanced Critical Care, 27(1), 111-119. https://doi.org/10.4037/aacnacc2016275

Schmitt, M. H., Gilbert, J. H., Brandt, B. F., \& Weinstein, R. S. (2013, April). The coming of age for interprofessional education and practice. The American Journal of Medicine, 126(4), 284-288. https://doi.org/10.1016/j.amjmed.2012.10.015

Schooley, B., Hikmet, N., Tarcan, M., \& Yorgancioglu, G. (2016). Comparing Burnout Across Emergency Physicians, Nurses, Technicians, and Health Information Technicians Working for the Same Organization. Medicine, 95(10). https://doi.org/10.1097/MD.0000000000002856

Schwarzer, R., \& Jerusalem, M. (1995). The General Self-Efficacy Scale (GSE). Retrieved from https://userpage.fu-berlin.de/health/engscal.htm

Shinnick, M. A., \& Woo, M. A. (2014, February). Does nursing student self-efficacy correlate with knowledge when using human patient simulation? Clinical Simulation in Nursing, 10(2), e71-e79. https://doi.org/10.1016/j.ecns.2013.07.006

Sibler, E., \& Tippett, J. S. (1965). Self-esteem: Clinical assessment and measurement of validation. Psychological Reports, 16, 1017-1071. https://doi.org/10.2466/pr0.1965.16.3c.1017

Turner, S., \& Harder, N. (2018). Psychological safety environment: A concept analysis. Clinical Simulation in Nursing, 18(), 47-55. https://doi.org/10.1016/j.ecns.2018.02.004

World Health Organization [WHO]. (2010). Framework for action on interprofessional education and collaborative practice. Retrieved from http://www.who.int/hrh/resources/framework_action/en/.

Zorek, J., \& Raehl, C. (2012). Interprofessional education accreditation standards in the USA: A comparative analysis. Journal of Interprofessional Care, 27(2), 123-130. https://doi.org/10.3109/13561820.2012.718295

\section{Copyrights}

Copyright for this article is retained by the author(s), with first publication rights granted to the journal.

This is an open-access article distributed under the terms and conditions of the Creative Commons Attribution license (http://creativecommons.org/licenses/by/4.0/). 